\title{
Air travel when you have a lung condition
}

Having a lung condition should not stop you from travelling by air. Whether you are going on holiday, a business trip or a visit to family and friends, it should be possible to make the necessary arrangements - as long as you plan ahead.

This factsheet will cover the key things you should consider when planning a trip, and give you some tips on keeping well while you are abroad.

\section{Speak to your healthcare professional}

The first thing you should do before you plan your trip is to speak to your healthcare professional. It is best to do this as soon as possible, particularly as you might need to do some extra tests to check that you are fit enough to travel, which may result in needing oxygen or additional medication.

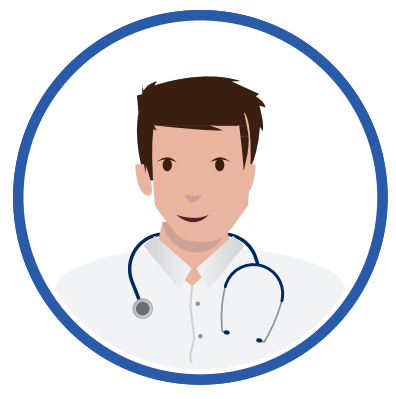

\section{In-flight oxygen - why you might need it}

The air on a plane contains less oxygen than the air we normally breathe in. This leads to lower levels of oxygen in the blood.

If you do not have a lung condition, the drop in oxygen is not enough that you would feel the difference.

If you have a lung condition, your oxygen levels may already be low, or your lungs may not be able to work properly to keep the amount of oxygen in your blood at a safe level. Lower levels of oxygen in your blood may make you feel unwell or could even be harmful to you during or after your flight. This means that, even if you do not usually need oxygen, you may need it while flying. Additional oxygen keeps the oxygen levels in your blood at

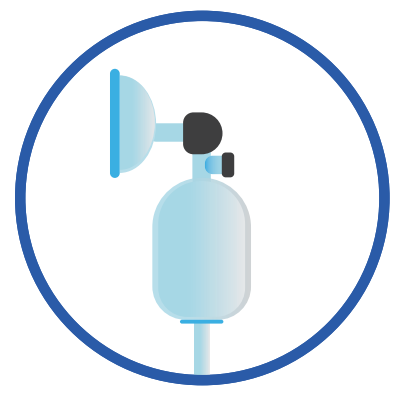
a comfortable level and keeps you safe.

If you already use oxygen, flying may mean that you have to increase your flow rate. 
"I don't normally need oxygen, but during a check-up I mentioned in passing to my doctor that I had a holiday coming up she told me I would need to do a fit to fly test. It turned out that I would need oxygen for the 7-hour flight - so I am glad that it came up in my appointment."

\section{The hypoxic challenge - or fit to fly - test}

To find out if you need in-flight oxygen, you may need to do a hypoxic challenge - or fit to fly - test.

First, your doctor will take some blood from you to check what your oxygen levels are like normally (a blood gas test). If your oxygen levels are already low at this stage, your doctor will recommend that you take oxygen on your flight.

If your oxygen levels are OK, your healthcare professional may still think you could be at risk and ask you to take the fit to fly test. The test involves breathing air that contains a similar level of oxygen to the amount found on an aeroplane through a face mask or mouthpiece for up to 20 minutes. Your healthcare professional will stay with you during the test to monitor your response. Your oxygen levels will be measured using a device called an oximeter, which shines a small light through your finger, ear or forehead to measure your oxygen levels. If it shows that your oxygen levels have fallen below the recommended amount, your doctor will stop the test and check your oxygen levels with another blood test. If the test continues for the full 20 minutes, your doctor will take another blood sample at the end of the test to check your oxygen levels.

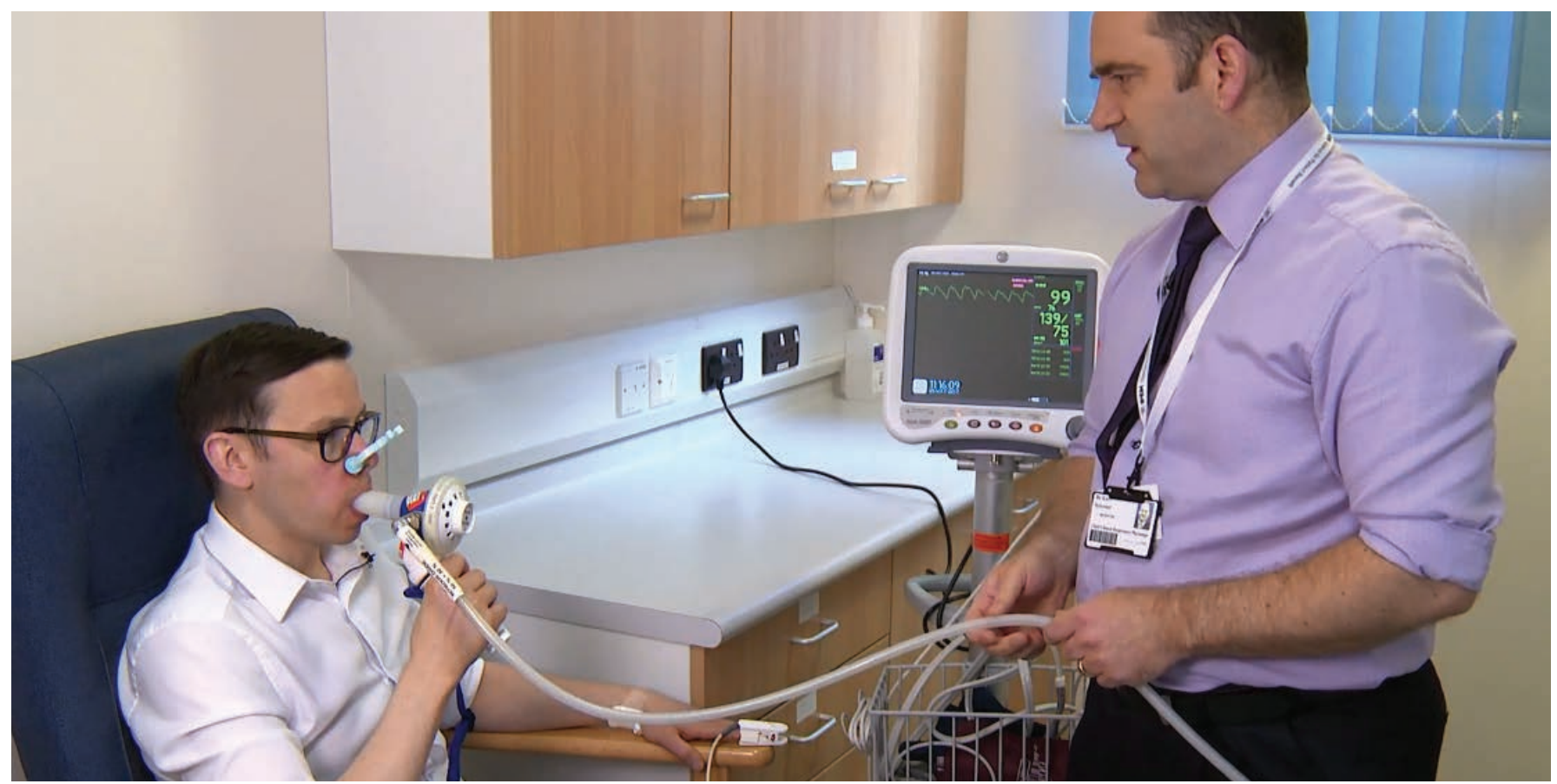


If the amount of oxygen in your blood falls below the recommended level, you will need in-flight oxygen.

Your healthcare professional may decide how much oxygen you need (flow rate) based on the results of the test and your general health. In other cases, you will need to do an extra test called a titration study. This involves repeating the fit to fly test while breathing in different levels of additional oxygen to see which flow rate helps your oxygen levels to recover.

Your doctor will usually tell you how long your test results are valid for. As long as your condition stays the same, the results should stay valid. If it changes (i.e. flare-ups, lower levels of oxygen in the blood), you will need to take the test again when you next fly. You can watch a video about the fit to fly test on the ELF website.

\section{Check the airline's oxygen policy}

If you require oxygen during your flight, you should check the airline's oxygen policy. Policies vary between airlines - some provide in-flight oxygen, which you will often have to pay for. The amount charged varies between carriers. Others will allow you to bring your own Federal Aviation Administration (FAA) approved portable oxygen concentrator (POC) onto the flight, but will often specify the type of device you can use.

You should speak to your airline as early as possible to make sure that they are able to accommodate your needs. If you are taking your own POC, check that your device is permitted, and make sure that you have enough batteries to comfortably last for the whole flight - bringing extra for any potential delays.

Visit the airline index on our website, which lists the oxygen policies and contact details of each major airline.

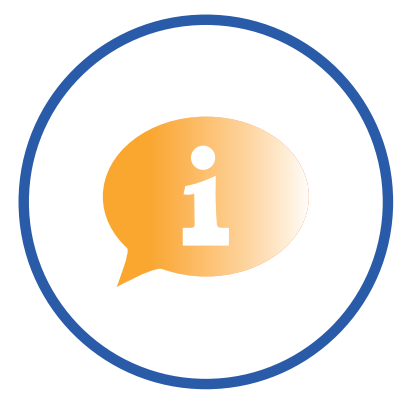

\section{Informing the airline - medical certificate}

If you need additional oxygen on board the plane, your airline will ask for a medical certificate, commonly referred to as a Fit to Fly Certificate or MEDIF (Medical Information Form). These certificates show that you are healthy enough to fly. You or your carer will need to fill in part of the form, and your doctor will need to fill in the other part. 
Each airline has its own form that can be downloaded from their website - usually on the special assistance pages. If it is not online, you will have to contact the special assistance department of the airline.

Only some of the information requested in the form may be relevant for you. They are designed to cover different temporary or long-term conditions, including heart problems, recent surgeries and injuries.

Generally, you will need to give details of the following:

- Your route, flight date and booking reference

- Your oxygen needs (if applicable), including rates in litres per minute and flow type (continuous or pulse)

- Medical equipment you will be taking (e.g. POC, continuous positive airway pressure (CPAP) machines, mobility equipment)

- Battery information for the above equipment

- Who you will be travelling with (if applicable) so that you can sit next to each other during the journey

Passengers are usually responsible for signing and sending the form. Always read the instructions on how to complete it, and when and who to send it to.

\section{Arranging special assistance}

You should consider requesting special assistance both at the airport and your destinations. Airports can be very big places where you may have to walk for long distances (e.g. from the front door to the departure gate) or stand for a long time due to lack of seating.

Even if your flight is on time, getting to your plane might take longer than you expect. With special assistance, you will be able

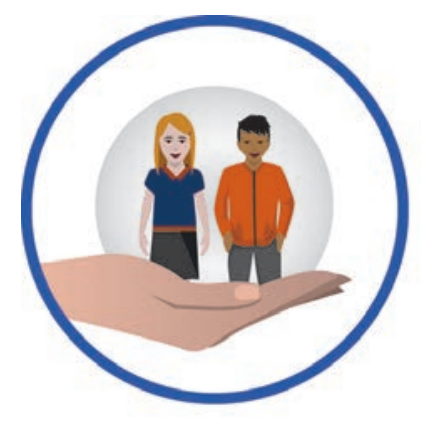
to arrive at your destination more relaxed.

Airlines will arrange special assistance for you, which will be provided by the airport. You will need to arrange it in advance, at least 48 hours before the trip. Airport websites usually have a directory with links to special assistances pages of airlines. Also consider any stop-offs.

"Airports can be very difficult to get around. Once I was at an airport, with special assistance, and the toilets were down a flight of stairs without a lift. Luckily I had my POC, but it took me about 10 minutes to get up and down". 


\section{Make arrangements for your destination}

If you need oxygen for the rest of your holiday, you should arrange it before you travel. Your healthcare professional or oxygen supplier may be able to recommend a supplier in your destination country.

If you have a European Health Insurance Card (EHIC), you may be able to arrange oxygen through the scheme, which gives access to medically necessary, stateprovided healthcare during a temporary stay in any of the EU countries, Iceland, Liechtenstein, Norway and Switzerland, under the same conditions and at the same cost (free in some countries) as people insured in that country. Some countries will have a list of providers they have agreements with for this scheme, so it is worth checking. Make sure that your oxygen provider is able to meet your requirements for your holiday. You should also check that your accommodation is able to receive delivery of the oxygen, and whether there are any other things to consider - for example, you may need a ground floor room or you may want to check levels of air pollution. It is also worth keeping the contact details of your oxygen supplier with you and familiarising yourself with their office hours in case of any problems.

If you have one, bring your EHIC with you and keep it with you at all times in case you suddenly need medical treatment.

You should also make sure that you have adequate travel insurance to cover you while you are away, and that you tell them about your lung condition - as not doing so could mean that your policy is not valid, meaning that you may face a large medical bill if you fall ill while on holiday. Bring your insurance documents with you and keep them safe.

\section{In summary, remember to:}

- Start making arrangements as early as possible, allowing yourself plenty of time.

- Speak to your doctor to check your oxygen requirements, and ask if there is anything else you can do to prepare.

- If your doctor recommends that you fly with additional oxygen, check the airline's oxygen policy.

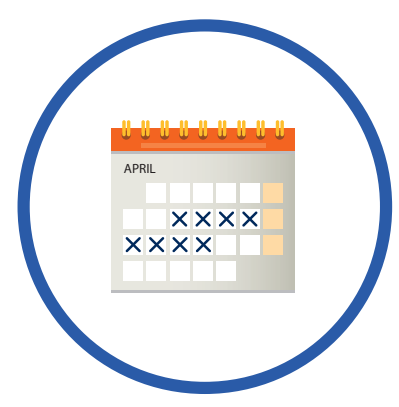

- Arrange oxygen for your flight - and also at your destination.

- Fill out your medical certificate (fit to fly form/MEDIF) with your healthcare professional, giving details about your condition; your medical equipment and oxygen needs; and your escort/travel companion, if applicable. 
- Request special assistance, both in the airport and at your destination.

- Check a map of the airport for the location of special assistance desks, power sockets, toilets and other facilities.

- Bring your essentials in your hand luggage: medications; medical equipment (e.g. POC or CPAP), with enough batteries and documentation to show airport staff; EHIC and insurance policy information; and plug adaptors (if applicable).

- On the day of the flight, allow yourself plenty of time at the airport. Drink lots of water and consider taking flight socks and nasal spray with you.

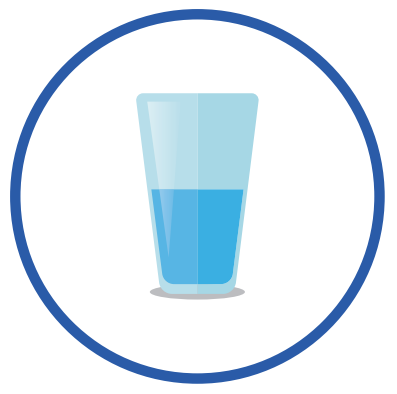

\section{Further reading and useful links}

\section{- European Lung Foundation website section on air travel:} www.europeanlung.org/airtravel

Access the airline index for oxygen policies; information on the fit to fly test, getting a medical certificate and arranging special assistance; and practical tips.

- European Union website - rights for travellers with reduced mobility: https://europa.eu/youreurope/citizens/travel/transport-disability/reduced-mobility Get information on your rights when travelling in the EU.

\section{- European Health Insurance Card:}

http://ec.europa.eu/social/main.jsp?catld=559

A free card that gives access to medically necessary, state-provided healthcare during a temporary stay in any of the EU countries, Iceland, Liechtenstein, Norway and Switzerland, under the same conditions and at the same cost (free in some countries) as people insured in that country. A smartphone app, which features comprehensive information for each country covered by the scheme, is also available.

\section{Tell us how it went - good or bad, we want to know!}

Hearing your experiences helps us improve the advice we give to people in a similar position and to give feedback to airlines, airports and oxygen providers. Email us: info@europeanlung.org

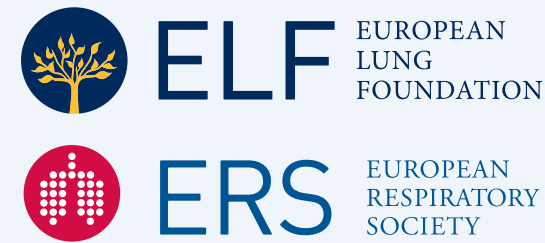
The European Lung Foundation (ELF) was founded by the European Respiratory Society (ERS),
with the aim of bringing together patients, the public and respiratory professionals to positively
influence respiratory medicine. ELF is dedicated to lung health throughout Europe, and draws
together the leading European medical experts to provide patient information and raise public
awareness about lung disease.

This material was compiled as part of the air travel project with the help of Dr Karl Sylvester, Matthew Rutter, Malcolm Weallans, Isabel Saraiva, Joy Wadsworth and Deborah Wellington.

Produced in June 2018. 